\title{
Might radiation therapy in addition to chemotherapy improve overall survival of patients with non-oligometastatic Stage IV non-small cell lung cancer?: Secondary analysis of two prospective studies
}

\author{
ShengFa Su ${ }^{1,2+}$, YinXiang Hu ${ }^{1,2+}$, WeiWei Ouyang ${ }^{1,2}$, Zhu Ma ${ }^{1,2}$, QingSong Li ${ }^{1,2}$, HuiQin Li $i^{1,2}, Y u$ Wang ${ }^{1,2}$,
}

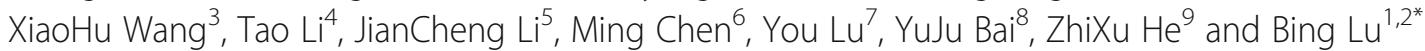

\begin{abstract}
Background: The role of radiation therapy in addition to chemotherapy has not been well established in nonoligometastatic Stage IV non-small cell lung cancer (NSCLC). We aimed to investigate overall survival (OS) of nonoligometastatic Stage IV NSCLC treated with chemotherapy with concurrent radiation to the primary tumor.

Methods: Eligible patients were screened from two prospective studies. Oligometastatic and non-oligometastatic NSCLC were defined as having $<5$ and $\geq 5$ metastatic lesions, respectively. Prognostic factors for OS were identified by using univariate and multivariate analysis. Landmark analysis and propensity-score matching (PSM) were each performed to further adjust for confounding.

Results: A total of 274 patients were identified as the study cohort: 183 had non-oligometastatic disease. For all 274 patients, those who received a radiation dose $\geq 63$ Gy to the primary tumor and had oligometastatic disease had better OS ( $P<0.001$ and $P=0.017$, respectively). When patients were subdivided into those with oligometastatic or non-oligometastatic disease, a radiation dose $\geq 63$ Gy remained a significant prognostic factor for better OS. For non-oligometastatic patients, multivariate analysis showed that receiving $\geq 63$ Gy radiation, having a GTV $<146 \mathrm{~cm}^{3}$, having response to chemotherapy, and having stable or increased post-treatment KPS independently predicted better OS $(P=0.018, P=0.014, P=0.014$, and $P=0.001)$. After PSM in non-oligometastatic patients, a higher radiation dose ( $\geq 63 \mathrm{~Gy}$ ) remained to be correlated with better OS. By landmark analysis, aggressive radiation ( $\geq 63 \mathrm{~Gy}$ ) remained to be correlated with better OS in Pre-PSM cohort $(P=0.005)$ and Post-PSM cohort $(P=0.004)$.
\end{abstract}

Conclusions: Radiation dose, primary tumor volume, response to chemotherapy and KPS after treatment are associated with OS in patients with non-oligometastatic disease; on basis of effective system chemotherapy, aggressive thoracic radiotherapy may prolong OS.

Keywords: Non-small cell lung cancer, Non-oligometastase, Thoracic three-dimensional radiotherapy, Overall survival

\footnotetext{
* Correspondence: Ibgymaaaa@163.com

${ }^{\dagger}$ Equal contributors

'Department of Thoracic Oncology, Affiliated Hospital of Guizhou Medical

University, and Guizhou Cancer Hospital, Guiyang 550004, China

${ }^{2}$ Teaching and Research Section of Oncology, Guizhou Medical University,

Guiyang 550004, China

Full list of author information is available at the end of the article
} 


\section{Background}

Approximately $60 \%$ of patients who have been newly diagnosed with non-small cell lung cancer (NSCLC) have distant metastases [1]. The metastatic status of NSCLC are highly variable, which ranges from the presence of a single metastatic lesion to a single organ to multiple lesions in several organs. Hellman et al. [2] proposed a notion is that of oligometastases in 1995, oligometastases is the state in which the patient shows distant metastase are limited in number and locations. In addition to oligometastases, there are many other patients who have extensive and widespread metastases, this metastatic state might be called "non-oligometastases".

In the era of two-dimensional radiotherapy (2D-RT), thoracic radiotherapy has long been used as a palliative care in metastatic NSCLC [3-5]. Recent years, there is increasing evidence showed that patients presenting with oligometastatic NSCLC could benefit from aggressive thoracic radiotherapy beyond palliative irradiation [6-12]. However, there was no consistent definition of oligometastases in these studies.

Although, the term of oligometastatic NSCLC has been used without a consistent definition. In recent years, the general opinion is that patients with 1-5 metastases is oligometastases [7-9, 13]. In general consideration, pharmacotherapy was the main treatment modality, and, radiation to primary tumor not affect survival and should be only given to alleviate symptoms (hemoptysis, cough, pain, and others) in nonoligometastatic Stage IV NSCLC. Thus, research on the treatment modalities for non-oligometastatic NSCLC have mainly focused on pharmacotherapy over the years. Nearly $30 \%$ of patients may benefit from molecular targeted therapy [14, 15]. Thus, approximately $70 \%$ of patients require system chemotherapy. However, the efficacy of platinum-based combination chemotherapy may have reached a plateau over the past 10-15 years [16, 17].

Radiation to the primary tumor for oligometastatic NSCLC patients, who had $<5$ metastases, has produced favorable survival outcomes $[7-10,13]$. In the early years, published data have indicated that the combination of thoracic radiotherapy and chemotherapy improved the treatment outcomes for limited-stage small-cell lung cancer (SCLC) patients [18, 19]. Recently, a phase 3 randomized controlled trial showed thoracic radiotherapy also improves OS for patients with extensive-stage SCLC who have responded to chemotherapy [20]. The remained question is that whether or not thoracic radiation therapy in addition to chemotherapy is beneficial for overall survival in patients with nonoligometastatic NSCLC (who had $\geq 5$ metastases), like extensive SCLC. Therefore, we collected clinical data from two prospective studies to analyze the survival outcomes of non-metastatic NSCLC patients who had undergone concurrent chemotherapy with threedimensional radiation therapy (3D-RT) to primary tumor and to determine prognostic factors in this population.

\section{Methods \\ Patient selection}

We selected patients presenting with metastaic NSCLC who were enrolled in two prospective studies from January 2003 and May 2012 [11, 12]. The selection criteria were as follows: (1) histologically or cytology confirmed NSCLC; (2) newly diagnosed stage IV disease (staged according to the 2002 system of the American Joint Committee on Cancer); (3) did not receive targeted therapy or immunotherapy during lifetime; (4) age 18-80 years; (5) a Karnofsky Performance Status (KPS) score $\geq 70 \%$; (6) received at least two chemotherapy cycles and a thoracic radiation dose of at least 36 Gy in 1.8 to 2-Gy fractions; (7) using modern radiation technique (3-dimensional conformal radiation therapy [3DCRT] or intensity modulated radiation therapy [IMRT]) and (8) had complete medical records (include sex, age, KPS score, tumor histology, $\mathrm{N}$ stage, $\mathrm{T}$ stage, metastatic status at diagnosis, radiation therapy to primary tumor, treatment response, and having survival outcomes [dead or alive]). This study was reviewed by the ethical review boards in China (Ethics Committee of Guizhou Cancer Hospital, GuiYang, China), and the informed consent was obtained from all patients.

\section{Definition of oligometastatic and non-oligometastatic disease}

The definition of oligometastatic and non-oligometastatic disease in NSCLC varies across studies, which ranges from the presence of a single metastatic lesion to a single organ in some studies to multiple lesions in several organs in others $[6,7,9,11,21,22]$. In our current study, we defined oligometastatic and non-oligometastatic NSCLC according to the number of metastatic lesions; namely that $<5$ metastatic lesions was defined as oligometastatic NSCLC, and $\geq 5$ metastatic lesions was defined as non- oligometastatic NSCLC.

\section{Pretreatment evaluations}

All patients underwent fiberoptic bronchoscopy and contrast-enhanced computed tomography $(\mathrm{CT})$ of the chest to evaluate the extent of the primary tumor and regional lymph node status. All patients also underwent bone scintigraphy, contrast-enhanced $\mathrm{CT}$ of the abdominal region, and magnetic resonance imaging (MRI) of the brain to detect distant metastases. Positive findings on positron emission tomography (PET) /CT or bone scintigraphy required other additional radiologic confirmation (e.g., MRI or CT of bone). Pretreatment 
evaluations were to be completed within 2 weeks before treatment was begun.

\section{Treatment methods Radiotherapy}

All select patients received thoracic radiation dose of at least 36 Gy in 1.8-2-Gy fractions. Radiation to primary tumor was implemented by modern techniques (3DCRT or IMRT). Radiation therapy was given concurrently with the chemotherapy, beginning within 1 week after beginning the first course of chemotherapy. Details of the radiation therapy protocol have been reported previously $[11,12]$.

\section{Chemotherapy}

Platinum-based doublet chemotherapy (cisplatin in combination with docetaxel, paclitaxel, pemetrexed, or vinorelbine), given every 21-28 days concurrent with thoracic radiation therapy, was the first-line therapy for all patients. No induction chemotherapy was given prior to radiation. After thoracic radiotherapy was completed, patients demonstrating response or stable disease continued chemotherapy for a total of 4-6 cycles. No maintenance therapy was given.

\section{Evaluation of treatment response}

The treatment responses of tumors, including complete response (CR), partial response (PR), stable disease (SD), and progressive disease (PD), were evaluated according to the Response Evaluation Criteria in Solid Tumors system [23]. To evaluate treatment response of radiotherapy: $\mathrm{CR}$ or $\mathrm{PR}$ was evaluated as having response, whereas SD or PD as no response. However, to evaluate treatment response of chemotherapy: no change in size or shrinkage in any size of target lesions was evaluated as having response to chemotherapy, whereas increasing in any size of target lesions as no response.

\section{Statistical analyses}

The endpoints of this study was to evaluate overall survival (OS). The OS time was measured from the starting date of treatment. Statistical tests were done with Stata, version 11.2 software. The Kaplan-Meier method was used to calculate the OS, and the curves were compared with log-rank tests. Multivariate Cox regression analysis was used to identify the independent predictors of OS. All significant factors in univariate analysis were further tested in the multivariate analysis. Propensity-score matching (PSM) and landmark analysis requiring a minimum of 8 months OS were each performed in sensitivity studies to further adjust for confounding. All statistical tests were two-sided, and $P$ values $<0.05$ were considered to indicate statistical significance.

\section{Results}

\section{Overall treatment outcomes}

Totally, 274 eligible patients were included in this study, 91 patients had oligometastatic disease and 183 had non-oligometastatic disease. The follow-up period ranged from 2.0 to 64.0 months; at the time of last follow-up, 15 patients were still alive, and the median survival time for those patients was 40.0 months (range, 12.0-64.0 months). The median OS time for all patients was 13.0 months (95\% CI 11.9-14.1), and the OS rates were $50.7 \%$ at 1 year, $15.8 \%$ at 2 years, and $9.1 \%$ at 3 years. OS rates for patients who had received $\geq 63$ Gy

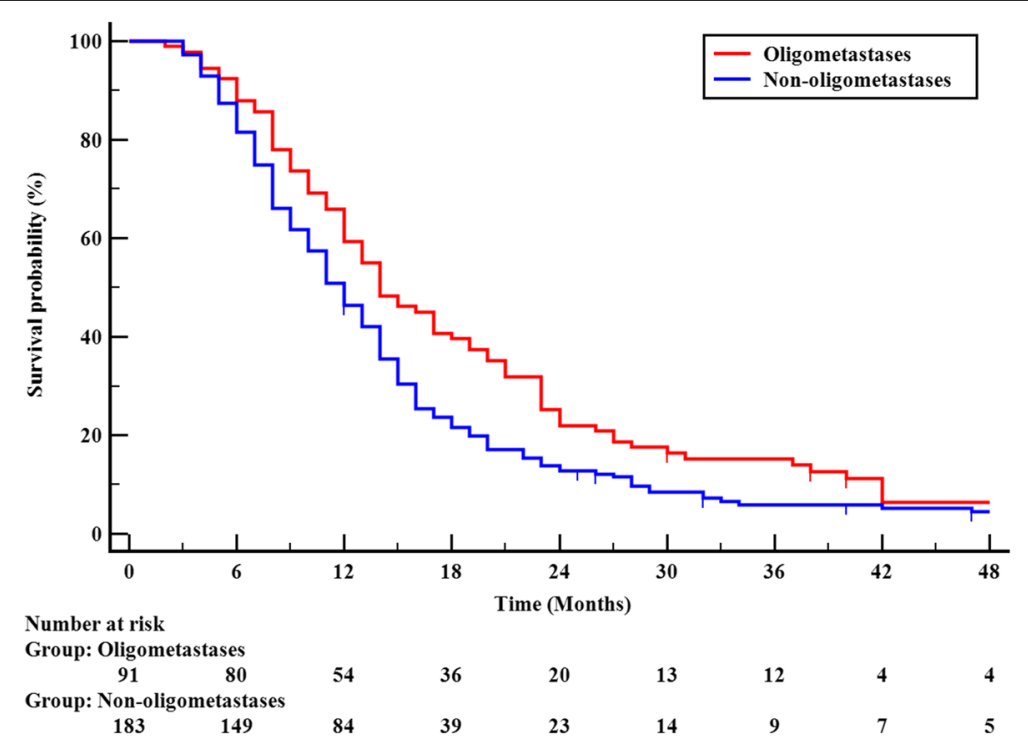

Fig. 1 Overall survival grouped by state of metastatic disease (oligometastases and non-oligometastases) 
thoracic radiation therapy were $55.3 \%$ at 1 year, $22.7 \%$ at 2 years, and $17.0 \%$ at 3 years; corresponding rates for those who received $<63$ Gy were $46.5 \%, 9.3 \%$, and $2.5 \%\left(X^{2}=15.638, P<0.001\right)$.

Comparison of OS in patients with oligometastatic disease versus those with non- oligometastatic disease, patients with oligometastatic disease had a better OS. The median survival time (MST) for these two groups were 14.0 months (95\% CI, 11.25 - 16.75) and 12.0 months (95\% CI, 10.59 - 13.41); the 1-, 2-, and 3-year OS rates were $59.3 \%, 22.0 \%$, and $15.2 \%$ versus $46.4 \%, 12.7 \%$, and 6.0\% $\left(X^{2}=5.741, P=0.017\right)$, (Fig. 1). When the whole group was subdivided into those with oligometastases $\left(x^{2}=6.150, \quad P=0.013\right)$ or non-oligometastases $\left(x^{2}=\right.$ $8.257, P=0.004)$, thoracic radiation dose $\geq 63$ Gy remained a prognostic factor for better overall survival.

Survival analysis of non-oligometastatic Stage IV patients Seventy-eight patients had metastasis in only one organ: 28 in the bone, 21 in the lung, 23 in the brain, and 6 in other locations. One hundred and five patients had metastasis in two or three organs, the most common site of metastatic disease at diagnosis was the bone (70 of 105 patients), 57 patients had lung metastasis, 51 had

Table 1 Characteristics of the non-oligometastatic patient cohort before and after PSM

\begin{tabular}{|c|c|c|c|c|c|c|}
\hline \multirow[t]{2}{*}{ Variable } & \multicolumn{3}{|c|}{ Pre-PSM Cohort } & \multicolumn{3}{|c|}{ Post-PSM Cohort } \\
\hline & $<63 \mathrm{~Gy}$ & $\geq 63 G y$ & $P$ value & $<63 \mathrm{~Gy}$ & $\geq 63 G y$ & $P$ value \\
\hline Total & 93 & 90 & & 59 & 59 & \\
\hline \multicolumn{7}{|l|}{ Gender } \\
\hline Male & 66 & 59 & 0.431 & 47 & 38 & 0.065 \\
\hline Female & 27 & 31 & & 12 & 21 & \\
\hline \multicolumn{7}{|l|}{ Age (years) } \\
\hline$<60$ years & 52 & 48 & 0.726 & 31 & 27 & 0.461 \\
\hline$\geq 60$ years & 41 & 42 & & 28 & 32 & \\
\hline \multicolumn{7}{|l|}{ KPS Score } \\
\hline$\leq 80$ & 58 & 52 & & 32 & 32 & \\
\hline$>80$ & 35 & 38 & 0.526 & 27 & 27 & 1.000 \\
\hline \multicolumn{7}{|l|}{ Pathological type } \\
\hline Squamous carcinoma & 35 & 24 & 0.048 & 24 & 20 & 0.651 \\
\hline adenocarcinoma & 47 & 61 & & 30 & 35 & \\
\hline Other & 11 & 5 & & 5 & 4 & \\
\hline \multicolumn{7}{|l|}{ T status } \\
\hline$T_{1-2}$ & 33 & 36 & 0.529 & 19 & 22 & 0.562 \\
\hline$T_{3-4}$ & 60 & 54 & & 40 & 37 & \\
\hline \multicolumn{7}{|l|}{ N status } \\
\hline $\mathrm{N}_{0-1}$ & 11 & 14 & 0.463 & 5 & 12 & 0.066 \\
\hline $\mathrm{N}_{2-3}$ & 82 & 76 & & 54 & 47 & \\
\hline \multicolumn{7}{|c|}{ Response to chemotherapy } \\
\hline Yes & 64 & 68 & & 43 & 43 & 1.000 \\
\hline No & 29 & 22 & 0.309 & 16 & 16 & \\
\hline \multicolumn{7}{|c|}{ No. of chemotherapy cycles } \\
\hline$<4$ & 63 & 32 & $<0.001$ & 30 & 30 & 1.000 \\
\hline$\geq 4$ & 30 & 58 & & 29 & 29 & \\
\hline \multicolumn{7}{|l|}{ GTV volume $\left(\mathrm{cm}^{3}\right)$} \\
\hline$<146$ & 44 & 40 & 0.697 & 23 & 23 & 1.000 \\
\hline$\geq 146$ & 49 & 50 & & 36 & 36 & \\
\hline \multicolumn{7}{|l|}{ Metastasis status } \\
\hline Single organ & 37 & 41 & 0.430 & 23 & 27 & 0.456 \\
\hline 2 to 3 organs & 56 & 49 & & 36 & 32 & \\
\hline
\end{tabular}


metastasis in brain, 16 had metastasis in adrenal, 12 patients had metastasis in distant lymph nodes, six had subcutaneous nodules, and 12 in other locations. Clinical characteristics of non- oligometastatic NSCLC patients are listed in Table 1.

At the time of analysis, 41 of 183 non-oligometastatic Stage IV patients died of unknown causes. The cause of death of the remaining142 patients were as follows: most patients died with distant metastasis, only 9 of 142 (6.3\%) patients died with primary recurrence alone, 95 (67.0\%) patients died with distant metastasis, 13 (9.2\%) patients died with distant metastasis and primary recurrence, $12(8.4 \%)$ patients died of other medical disease, 3 (2.1\%) patients died with treatment complication, and 10 (7.0\%) patients was alive. Univariate analysis showed that radiation dose to the primary tumor (Fig. 2), primary tumor volume, post-treatment KPS score, the number of chemotherapy cycles, and having a treatment response to chemotherapy were significantly associated with OS (Table 2). Multivariate analysis showed that radiation dose, primary tumor volume, post-treatment KPS score, and the treatment response to chemotherapy were significantly associated with OS, as shown in Table 3.

In subgroup analyses, we observed that radiation dose also interacted with treatment response to chemotherapy and primary tumor volume in terms of influencing OS. Total1y, $72.1 \%(132 / 183)$ patients were confirmed to have responded to chemotherapy, and $27.9 \%$ (51/183) patients have no response to chemotherapy. Among patients who had a response to chemotherapy, patients who received $\geq 63$ Gy to the primary tumor had a better OS than those received $<63$ Gy $\left(X^{2}=4.419, P=0.036\right)$; patients who had no response to chemotherapy, radiation doses was not correlated with OS $\left(\chi^{2}=1.947\right.$, $P=0.163$ ), Fig 3 . Patients with GTV $<146 \mathrm{~cm}^{3}$, radiation dose to primary tumor was not associated with OS $\left(x^{2}=\right.$ 1.248, $P=0.264)$; among patients with GTV $\geq 146 \mathrm{~cm}^{3}$, a higher radiation dose ( $\geq 63$ Gy) remained beneficial for OS $\left(\chi^{2}=7.897, P=0.005\right)$, Fig 4 .

\section{Propensity score analysis of the impact of radiation dose on OS in non-oligometastatic Stage IV patients}

The patient selection factors used to estimate the propensity score were KPS scores, GTV volume, number of chemotherapy cycles and response to chemotherapy. Table 1 summarizes the non-oligometastatic patient characteristics before and after PSM. Before PSM, there were significant differences in pathological type and the number of chemotherapy cycles between the groups that received $<63$ Gy and $\geq 63$ Gy. After PSM, all clinical characteristic were balanced between the two radiation arms. The 1:1 propensity score-matched cohort consisted of 118 patients with non-oligometastatic disease.

In the post-PSM cohort, radiation dose to the primary tumor, having a treatment response to chemotherapy, and post-treatment KPS score a1so remained to be associated with OS, and the number of chemotherapy cycles had a trend for better OS by univariate analysis (Table 2). On multivariate analysis, these factors retained significance with regard to OS, as shown in Table 3. On landmark analysis for patients surviving at least 8 months, patients who received $\geq 63$ Gy to primary tumor retained significance with better OS in PrePSM cohort $\left(X^{2}=7.953, \quad P=0.005\right)$ and post-PSM cohort $\left(X^{2}=8.157, P=0.004\right)$.

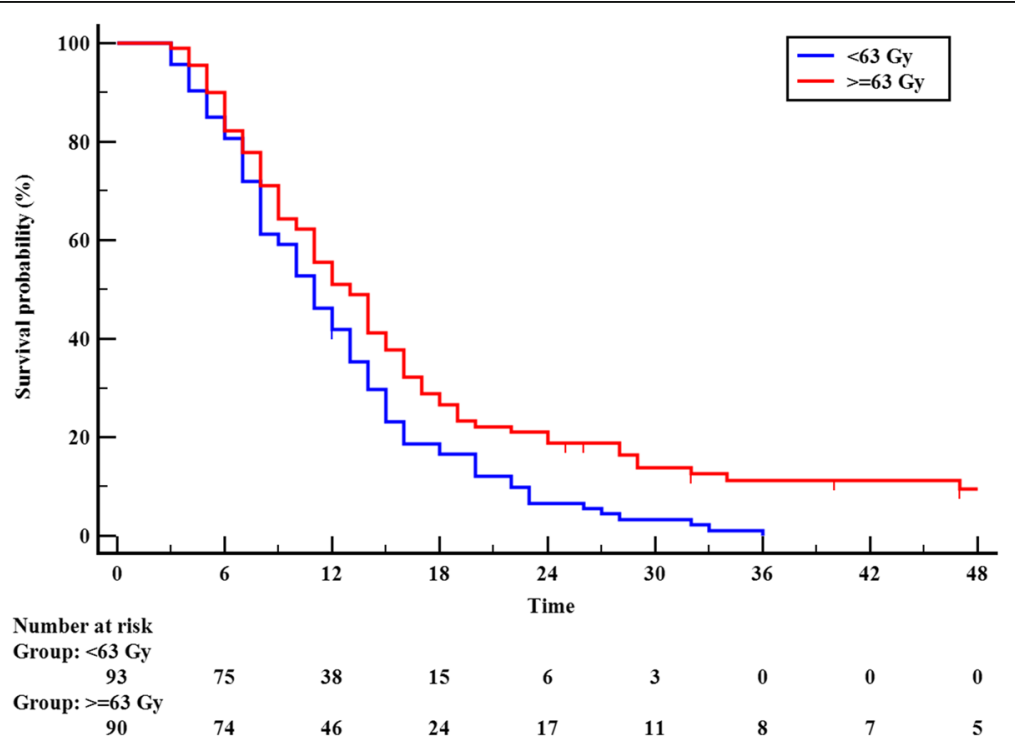

Fig. 2 Overall survival in non-oligometastases patients according to radiation dose 
Table 2 Univariate analysis for OS in non-oligometastatic patients

\begin{tabular}{|c|c|c|c|c|c|c|c|c|c|c|}
\hline \multirow[t]{2}{*}{ Variable } & \multicolumn{5}{|c|}{ Pre-PSM Cohort } & \multicolumn{5}{|c|}{ Post-PSM Cohort } \\
\hline & No & $1-y r$ & $2-y r$ & $3-y r$ & Statistic value & No & $1-y r$ & $2-y r$ & $3-y r$ & Statistic value \\
\hline \multicolumn{11}{|l|}{ Gender } \\
\hline Male & 125 & 41.6 & 12.8 & 4.3 & $x^{2}=1.804$ & 85 & 36.5 & 11.8 & 3.5 & $x^{2}=2.153$ \\
\hline Female & 58 & 56.9 & 12.4 & 7.8 & $P=0.179$ & 33 & 7.6 & 12.1 & 6.1 & $P=0.142$ \\
\hline \multicolumn{11}{|l|}{ Age (years) } \\
\hline$<60$ & 100 & 48.0 & 11.0 & 3.7 & $x^{2}=0.009$ & 58 & 44.8 & 12.1 & 4.0 & $x^{2}=0.295$ \\
\hline$\geq 60$ & 83 & 44.6 & 14.9 & 7.4 & $P=0.926$ & 60 & 40.0 & 11.7 & 6.7 & $P=0.587$ \\
\hline \multicolumn{11}{|l|}{ Tumor histology } \\
\hline Adenocarcinoma & 108 & 52.8 & 14.1 & 6.4 & $x^{2}=2.777$ & 65 & 41.5 & 12.3 & 6.6 & $x^{2}=0.443$ \\
\hline Squamous carcinoma & 59 & 37.3 & 10.2 & 5.1 & $P=0.250$ & 44 & 40.9 & 9.1 & 4.5 & $P=0.801$ \\
\hline others & 16 & 37.5 & 12.5 & 0.0 & & 9 & 55.6 & 11.1 & 0.0 & \\
\hline \multicolumn{11}{|l|}{ Pre-treatment KPS } \\
\hline $70-80$ & 110 & 49.1 & 12.0 & 5.6 & $x^{2}=0.255$ & 64 & 43.8 & 7.8 & 4.7 & $x^{2}=0.001$ \\
\hline$>80$ & 73 & 42.5 & 13.7 & 4.3 & $P=0.614$ & 54 & 40.7 & 16.7 & 5.2 & $P=0.976$ \\
\hline \multicolumn{11}{|l|}{ T stage } \\
\hline $\mathrm{T} 1-2$ & 69 & 50.7 & 11.9 & 5.0 & $x^{2}=0.018$ & 41 & 39.0 & 9.8 & 4.9 & $x^{2}=0.862$ \\
\hline T3-4 & 114 & 43.9 & 13.2 & 4.8 & $P=0.914$ & 77 & 44.2 & 13.0 & 5.4 & $P=0.353$ \\
\hline \multicolumn{11}{|l|}{ N stage } \\
\hline No-1 & 25 & 68.0 & 21.3 & 11.3 & $x^{2}=3.696$ & 17 & 64.7 & 17.6 & 17.6 & $x^{2}=3.242$ \\
\hline $\mathrm{N} 2-3$ & 158 & 43.0 & 11.4 & 4.5 & $P=0.055$ & 101 & 38.6 & 10.9 & 3.6 & $P=0.072$ \\
\hline \multicolumn{11}{|l|}{ Gross tumor volume, $\mathrm{cm}^{3}$} \\
\hline$<146$ & 90 & 59.2 & 17.5 & 6.7 & $x^{2}=7.319$ & 46 & 50.0 & 10.9 & 4.3 & $x^{2}=0.618$ \\
\hline$\geq 146$ & 93 & 37.6 & 9.7 & 4.2 & $P=0.007$ & 72 & 37.5 & 12.5 & 6.2 & $P=0.432$ \\
\hline \multicolumn{11}{|l|}{ Post-treatment KPS } \\
\hline Increased or stable & 151 & 52.3 & 14.8 & 5.9 & $x^{2}=15.807$ & 95 & 47.4 & 13.7 & 5.7 & $x^{2}=6.011$ \\
\hline Decreased & 32 & 18.8 & 3.1 & 3.1 & $P=0.000$ & 23 & 21.7 & 4.3 & 4.3 & $P=0.014$ \\
\hline \multicolumn{11}{|l|}{ Radiation dose, Gy } \\
\hline$\geq 63$ & 90 & 51.1 & 21.1 & 11.2 & $x^{2}=8.257$ & 59 & 47.5 & 20.3 & 10.8 & $x^{2}=7.013$ \\
\hline$<63$ & 93 & 41.9 & 6.6 & 0.0 & $P=0.004$ & 59 & 37.3 & 3.4 & 0 & $P=0.008$ \\
\hline \multicolumn{11}{|l|}{ Chemotherapy cycles } \\
\hline$<4$ & 95 & 37.9 & 8.7 & 2.5 & $x^{2}=5.334$ & 60 & 31.7 & 6.7 & 4.4 & $x^{2}=3.775$ \\
\hline$\geq 4$ & 88 & 55.7 & 1.7 & 8.3 & $P=0.021$ & 58 & 53.4 & 17.2 & 6.5 & $P=0.052$ \\
\hline \multicolumn{11}{|l|}{ Metastasis status } \\
\hline Single organ & 78 & 46.2 & 16.7 & 8.3 & $x^{2}=1.622$ & 50 & 46.0 & 18.0 & 8.0 & $x^{2}=2.739$ \\
\hline 2 to 3 organs & 105 & 46.7 & 9.7 & 2.9 & $P=0.203$ & 68 & 39.7 & 7.4 & 3.7 & $P=0.098$ \\
\hline \multicolumn{11}{|c|}{ Response to chemotherapy } \\
\hline No & 51 & 25.5 & 7.8 & 3.9 & $x^{2}=10.428$ & 32 & 21.9 & 6.2 & 3.1 & $x^{2}=6.230$ \\
\hline Yes & 132 & 54.5 & 14.6 & 5.9 & $P=0.001$ & 86 & 50.0 & 14.0 & 6.1 & $P=0.013$ \\
\hline
\end{tabular}

Survival analysis of oligometastatic Stage IV patients

Among 91 oligometastatic Stage IV patients: most patients died with distant metastasis, only $11(12.1 \%)$ patients died with primary recurrence alone, 43 (47.3\%) patients died with distant metastasis, 15 (16.5\%) patients died with distant metastasis and primary recurrence, 5
(5.5\%) patients died of other medical disease, 12 (13.2\%) died of unknown causes, and 5 (5.5\%) patients was alive.

Univariate analysis showed that radiation dose to the primary tumor $\left(X^{2}=6.150, P=0.013\right)$, primary tumor volume $\left(X^{2}=5.433, P=0.020\right)$, post-treatment KPS score $\left(X^{2}=4.730, P=0.030\right)$, the number of chemotherapy 
Table 3 Multivariate analyses for OS in non-oligometastatic patient

\begin{tabular}{|c|c|c|c|c|c|c|c|c|}
\hline \multirow[t]{3}{*}{ Variable } & \multicolumn{4}{|c|}{ Pre-PSM Cohort } & \multicolumn{3}{|c|}{ Post-PSM Cohort } & \multirow{3}{*}{$P$ value } \\
\hline & \multirow[t]{2}{*}{$\mathrm{HR}$} & \multicolumn{2}{|c|}{ 95.0\% confidence interval } & \multirow[t]{2}{*}{$P$ value } & \multirow[t]{2}{*}{$\mathrm{HR}$} & \multicolumn{2}{|c|}{ 95.0\% confidence interval } & \\
\hline & & lower & upper & & & lower & upper & \\
\hline $\begin{array}{l}\text { Radiation dose, Gy } \\
\text { (<63 vs. } \geq 63 \text { ) }\end{array}$ & 1.481 & 1.071 & 2.047 & 0.018 & 1.656 & 1.125 & 2.438 & 0.011 \\
\hline $\begin{array}{l}\text { Response to chemotherapy } \\
\text { (No vs. Yes) }\end{array}$ & 1.541 & 1.092 & 2.176 & 0.014 & 1.643 & 1.073 & 2.517 & 0.022 \\
\hline $\begin{array}{l}\text { Post-treatment KPS } \\
\text { (Decreased vs. Increased or stable) }\end{array}$ & 1.958 & 1.319 & 2.907 & 0.001 & 1.704 & 1.064 & 2.729 & 0.026 \\
\hline $\begin{array}{l}\text { No. of chemotherapy cycles } \\
(\geq 4 \text { vs. }<4)\end{array}$ & 0.796 & 0.572 & 1.106 & 0.173 & - & - & - & - \\
\hline $\begin{array}{l}\text { Gross tumor volume, } \mathrm{cm}^{3} \\
(\geq 146 \text { vs. }<146)\end{array}$ & 1.479 & 1.082 & 2.021 & 0.014 & - & - & - & - \\
\hline
\end{tabular}

cycles $\left(X^{2}=4.384, P=0.036\right)$, and having a treatment response to chemotherapy $\left(X^{2}=7.444, P=0.006\right)$ were significantly associated with OS. Multivariate analysis showed that radiation dose $(P=0.047)$, and primary tumor volume $(P=0.015)$ predicted OS in these patients with oligometastatic Stage IV NSCLC.

\section{Discussion}

This study sought to investigate whether combining systemic chemotherapy with radiation to the primary tumor could further improve OS of non-oligometastatic Stage IV NSCLC. Compared with historical data [16, 24], this combined therapy in current study produce favorable overall survival. Consistent with previous publication [9], we found that oligometastatic disease and aggressive radiation to the primary tumor were associated with better OS. When the entire group was divided according to metastatic status (oligometastases vs. non-oligometastases), aggressive radiation doses to the primary tumor retained significance for predicting improved survival outcomes.

Consistent with the conclusion of previous studies $[7,9,10]$, we found that radiation dose, and primary tumor volume predicted survival in these patients with oligometastatic disease. Among patients with non-oligometastatic disease, defined as $\geq 5$ metastases, we found that receiving higher radiation dose to primary tumor, having a smaller GTV, having response to chemotherapy, and having stable or increased posttreatment KPS scores independently predicted better OS. Most of these predicted factors have been identified in the literature as positive prognostic factors in oligometastatic NSCLC $[7-9,12,25]$.

Non-oligometastatic NSCLC patients who are judged to be incurable and have a very short life expectance, radiation is most typically used as palliative treatment

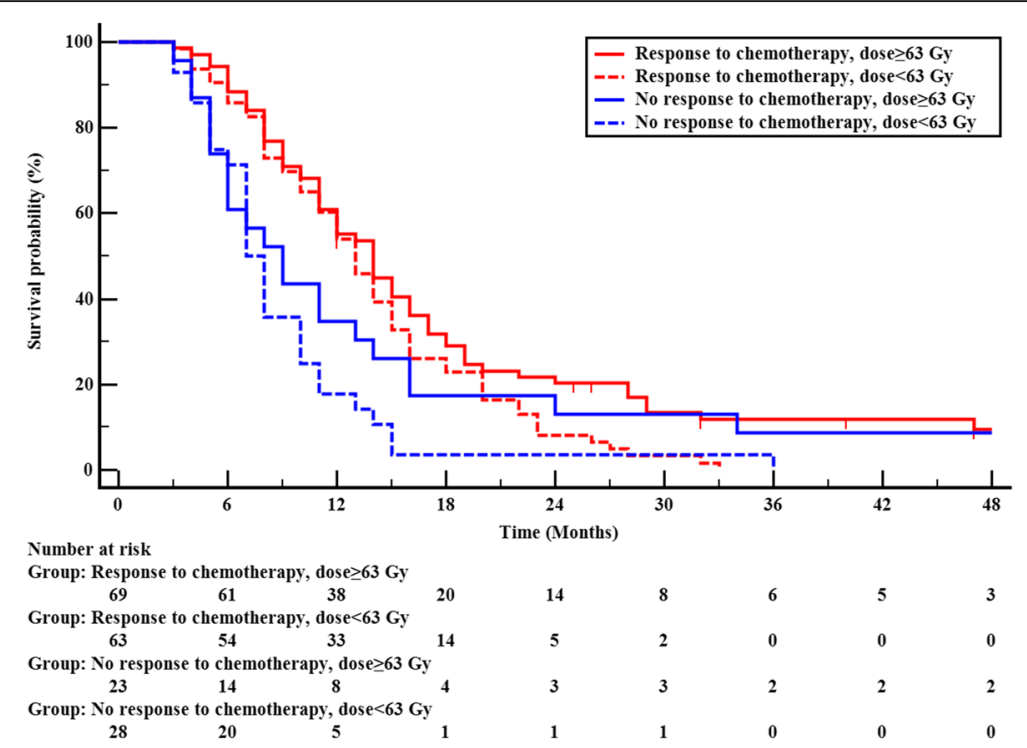

Fig. 3 Overall survival according to radiation dose and treatment response of chemotherapy 


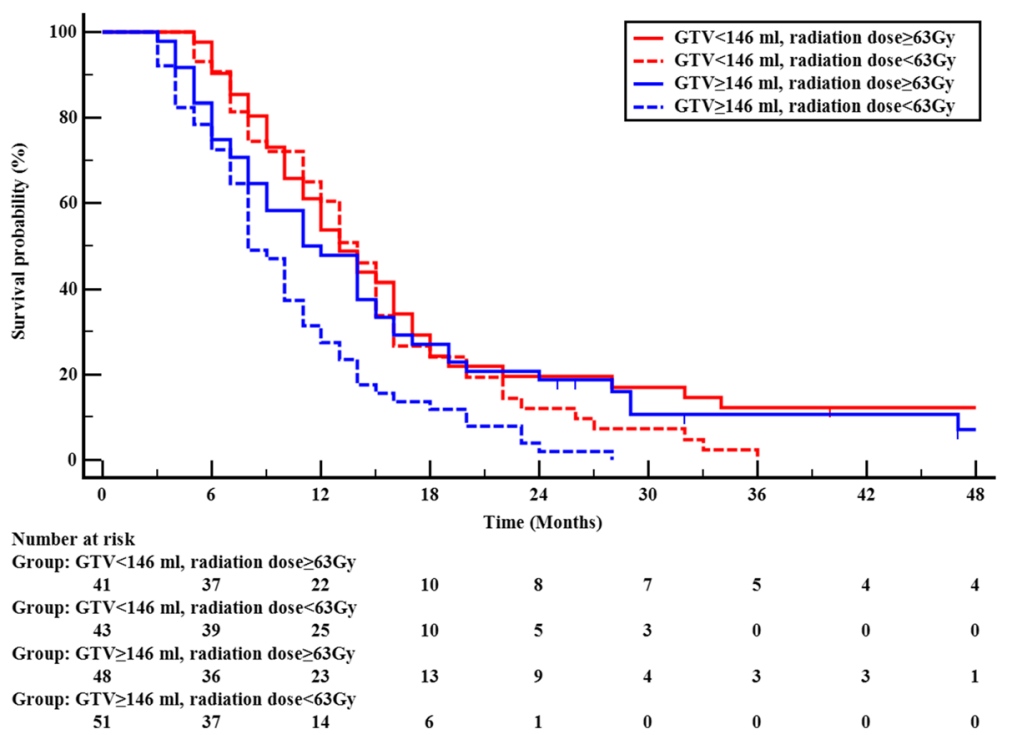

Fig. 4 Overall survival according to radiation dose and primary tumor volume

when symptoms (hemoptysis, cough, chest pain, dyspnea, and others) emerge. Recent years, there is increasing evidence that selected oligometastatic NSCLC patients could benefit from aggressive thoracic radiotherapy beyond palliative irradiation [7-9, 11, 21, 22]. Comparatively speaking, published studies concerning radiation doses (aggressive or palliative) for nonoligometastatic patients has been limited. In current study, receiving $\geq 63$ Gy to the primary tumor was an independent prognostic predictors of better OS.

Pharmacotherapy has been the main treatment modality, and still play an irreplaceable role for non-metastatic NSCLC. In current study, having response to chemotherapy was an independent prognostic predictors of better OS, and receiving $\geq 4$ cycles chemotherapy was marginally associated with better OS. When the entire group was divided according to response to chemotherapy, higher radiation doses to the primary tumor retained significance for predicting improved survival outcomes in patients who had response to chemotherapy. For the subgroup that had no response to chemotherapy, there was no benefit for improved OS at higher radiation doses. Our findings suggest that non-oligometastatic NSCLC patients benefit from higher radiation doses ( $\geq 63 \mathrm{~Gy}$ ) to the primary tumor based on effective systemic chemotherapy. Thus, in clinical practice, higher radiation dose may be apply in a patient cohorts who have treatment response to effective system therapy. For nonmetastatic NSCLC patients who have no response to system therapy, thoracic radiation therapy can be used for palliative intent, whereas, high dose radiotherapy is an unwise choice. In current study, radiation to primary tumor was given concurrently with the chemotherapy. As a result, we recommend further investigation on the value of radiation to primary tumor following effective induction chemotherapy on non-oligometastatic NSCLC.

Recent years, molecular targeted therapy and immunotherapy produce favorable survival outcomes in metastatic NSCLC patients [15, 26, 27]. Because no patients in the current study received molecular targeted therapy or immunotherapy, we cannot comment on whether thoracic radiation combined with molecular targeted therapy or immunotherapy would affect survival. Thus, additional studies are also necessary to investigate the value of thoracic radiation in combination with targeted therapy or immunotherapy for patients with nonoligometastatic NSCLC.

From a clinical standpoint, the larger primary tumor is an indication of a greater tumor burden and source of metastasis, and makes the tumor more difficult to control $[28,29]$. Our finding suggest that non-oligometastatic NSCLC patients with smaller primary tumor volume had better OS, consistent with the impact of primary tumor burden on OS for oligometastatic NSCLC [7, 8]. In addition, among patients with larger GTV $\left(\geq 146 \mathrm{~cm}^{3}\right)$, a higher radiation dose ( $\geq 63$ Gy) remained beneficial for OS; whereas, survival benefit was not observed with higher radiation dose in patients with GTV $<146 \mathrm{~cm}^{3}$. Our findings suggest that the volume of primary tumor may be used as an indicator to decide radiation dose to primary tumor. We found that stable or increased posttreatment KPS scores were independent predictors of better survival. This finding suggests that post-treatment performance status should be maintained or improved; thus, overtreatment should be avoided when treating nonoligometastatic NSCLC with multimodality therapy. 
We acknowledge several limitations of our study. First, consistent imaging data were not gained in a proportion of patients for the evaluation of the relationship between OS and control of primary tumor. Higher radiation doses are associated with improved local tumor control [30]. Although we did not obtain data regarding local control in this study, we speculate that aggressive radiation to primary tumor can improve OS by improving control of primary tumor to reduce the death rate caused by local growth of tumor and decrease the sources of metastasis. Second, the choice of the radiation dose may depend on some factors such as KPS and tumor burden. Although PSM, multivariate regression and landmark analysis were used to reduce this bias, some unaccounted confounders could still have existed between the treatment groups because of the retrospective nature of this study. Therefore, further evidence is needed to confirm conclusions of this study.

\section{Conclusions}

Patients with non-oligometastatic Stage IV NSCLC with good performance status who were treated with aggressive radiation doses ( $\geq 63 \mathrm{~Gy}$ ) to the primary tumor had improved survival outcomes. However, patients benefit from aggressive radiation doses ( $\geq 63 \mathrm{~Gy}$ ) to the primary tumor based on having had response to effective system chemotherapy. Thus, in addition to systemic chemotherapy, we should consider proper radiation dose to primary tumor. Among patients with larger tumors, high radiation dose remained of benefit for OS, and primary tumor volume may be used as an criteria to decide radiation dose. Furthermore, the studies on radiation to primary tumor in non-oligometastatic NSCLC has been limited; and further studies, especially prospective studies, are needed to confirm the outcomes of this treatment modality.

\section{Abbreviations}

2D-RT: Two-dimensional radiotherapy; 3DCRT: 3-dimensional conformal radiation therapy; CR: Complete response; GTV: Gross tumor volume; IMRT: Intensity modulated radiation therapy; KPS: Karnofsky Performance Status; NSCLC: Non-small cell lung cancer; OS: Overall survival;

PD: Progressive disease; PR: Partial response; PSM: Propensity-score matching; SCLC: Small-cell lung cancer; SD: Stable disease

\section{Funding}

This work was supported by grants from the Science and Technology Office of Guizhou Province, China (No. SY 2012-3097, LG 2012-062, and SY 2014-3021); Guizhou Province's Science and Technology Major Project, China, No. Qian-JZhong[2015]2003. The funders had no role in study design, data collection and analysis, decision to publish or preparation of the manuscript.

\section{Availability of data and materials}

The datasets during and/or analysed during the current study available from the corresponding author on reasonable request.

\section{Authors' contributions}

Bing Lu designed the study. ShengFa Su, YinXiang Hu, Zhu Ma, WeiWei Ouyang, QingSong Li, HuiQin Li, Yu Wang, XiaoHu Wang, Tao Li, JianCheng Li, Ming Chen, You Lu, and YuJu Bai, collected the data. Bing Lu, ShengFa Su and YinXiang Hu undertook the data analysis and interpretation, and wrote the report. Bing Lu and ShengFa Su carried out the statistical analysis. All authors read and approved the final manuscript.

\section{Competing interests}

None of the authors have any financial disclosures or conflicts of interest to declare.

No actual or potential conflicts of interest exist.

Ethics approval and consent to participate

This study was reviewed by the ethical review boards in China

(Ethics Committee of Guizhou Cancer Hospital, GuiYang, China).

\section{Author details}

'Department of Thoracic Oncology, Affiliated Hospital of Guizhou Medical University, and Guizhou Cancer Hospital, Guiyang 550004, China. ${ }^{2}$ Teaching and Research Section of Oncology, Guizhou Medical University, Guiyang 550004, China. ${ }^{3}$ Department of Radiation Oncology, Gansu Cancer Hospital, Lanzhou 730050, China. ${ }^{4}$ Department of Radiation Oncology, Sichuan Cancer Hospital, Chengdu 610041, China. ${ }^{5}$ Department of Radiation Oncology, Fujian Provincial Cancer Hospital, Fuzhou 350013, China. ${ }^{6}$ Department of Radiation Oncology, Zhejiang Cancer Hospital, Hangzhou 310022, China. ${ }^{7}$ Department of Thoracic Oncology and State Key Laboratory of Biotherapy, Cancer Center, West China Hospital, Sichuan University, Chengdu 610041, China.

${ }^{8}$ Department of Oncology, Affiliated Hospital of Zunyi Medical College, Zunyi 563003, China. ${ }^{9}$ Tissue Engineering and Stem Cell Research Center of Guizhou Medical University, Guiyang 550004, China.

Received: 10 August 2016 Accepted: 21 October 2016

Published online: 21 November 2016

\section{References}

1. Siegel RL, Miller KD, Jemal A. Cancer statistics, 2015. CA Cancer J Clin. 2015; 65(1):5-29.

2. Hellman S, Weichselbaum RR. Oligometastases. J Clin Oncol. 1995:13(1):8-10.

3. Nestle $U$. Thoracic radiotherapy with 5 fractions may have palliative and survival benefits over single-fraction radiotherapy for people with lung cancer. Cancer Treat Rev. 2003;29(2):123-5.

4. Fairchild A, Harris K, Barnes E, Wong R, Lutz S, Bezjak A, Cheung P, Chow E. Palliative thoracic radiotherapy for lung cancer: a systematic review. J Clin Oncol. 2008:26(24):4001-11.

5. Rodrigues G, Videtic GMM, Sur R, Bezjak A, Bradley J, Hahn CA, Langer C, Miller KL, Moeller BJ, Rosenzweig K, et al. Palliative thoracic radiotherapy in lung cancer: An American society for radiation oncology evidence-based clinical practice guideline. Practical Radiat Oncol. 2011;1(2):60-71.

6. Cheruvu P, Metcalfe SK, Metcalfe J, Chen Y, Okunieff P, Milano MT. Comparison of outcomes in patients with stage III versus limited stage IV non-small cell lung cancer. Radiat Oncol. 2011:6:80.

7. Lopez Guerra JL, Gomez D, Zhuang Y, Hong DS, Heymach JV, Swisher SG, Lin SH, Komaki R, Cox JD, Liao Z. Prognostic impact of radiation therapy to the primary tumor in patients with non-small cell lung cancer and oligometastasis at diagnosis. Int J Radiat Oncol Biol Phys. 2012;84(1):e61-7.

8. Ashworth A, Rodrigues G, Boldt G, Palma D. Is there an oligometastatic state in non-small cell lung cancer? A systematic review of the literature. Lung Cancer. 2013;82(2):197-203.

9. Parikh RB, Cronin AM, Kozono DE, Oxnard GR, Mak RH, Jackman DM, Lo PC, Baldini EH, Johnson BE, Chen AB. Definitive primary therapy in patients presenting with oligometastatic non-small cell lung cancer. Int J Radiat Oncol Biol Phys. 2014:89(4):880-7.

10. Koshy M, Malik R, Mahmood U, Sher DJ. Comparative effectiveness of aggressive locoregional therapy in metastatic lung cancer: associations between high-dose thoracic radiation therapy and/or chemoradiation therapy and survival in a large population-based cohort. Int J Radiat Oncol Biol Phys. 2015;93(3):S68.

11. Su SF, Hu YX, Ouyang WW, Lu B, Ma Z, Li QS, Li HQ, Geng YC. Overall survival and toxicities regarding thoracic three-dimensional radiotherapy with concurrent chemotherapy for stage IV non-small cell lung cancer: results of a prospective single-center study. BMC Cancer. 2013;13(1):474.

12. Su S, Li T, Lu B, Wang X, Li J, Chen M, Lu Y, Bai Y, Hu Y, Ouyang W, et al. Three-Dimensional radiation therapy to the primary tumor with concurrent chemotherapy in patients with stage IV non-small cell lung cancer: results 
of a multicenter phase 2 study from PPRA-RTOG, China. Int J Radiat Oncol Biol Phys. 2015;93(4):769-77.

13. De Ruysscher D, Wanders R, van Baardwijk A, Dingemans AM, Reymen B, Houben R, Bootsma G, Pitz C, van Eijsden L, Geraedts W, et al. Radical treatment of non-small-cell lung cancer patients with synchronous oligometastases: long-term results of a prospective phase II trial (Nct01282450). J Thorac Oncol. 2012;7(10):1547-55.

14. Tanaka T, Matsuoka M, Sutani A, Gemma A, Maemondo M, Inoue A, Okinaga S, Nagashima M, Oizumi S, Uematsu K, et al. Frequency of and variables associated with the EGFR mutation and its subtypes. Int J Cancer. 2010; 126(3):651-5.

15. Qian H, Gao F, Wang H, Ma F. The efficacy and safety of crizotinib in the treatment of anaplastic lymphoma kinase-positive non-small cell lung cancer: a meta-analysis of clinical trials. BMC Cancer. 2014;14(1):683.

16. Scagliotti GV, De Marinis F, Rinaldi M, Crino L, Gridelli C, Ricci S, Matano E, Boni C, Marangolo M, Failla G, et al. Phase III randomized trial comparing three platinum-based doublets in advanced non-small-cell lung cancer. J Clin Oncol. 2002;20(21):4285-91.

17. Morgensztern D, Waqar S, Subramanian J, Gao F, Govindan R. Improving survival for stage IV non-small cell lung cancer: a surveillance, epidemiology, and end results survey from 1990 to 2005. J Thorac Oncol. 2009:4(12):1524-9.

18. Pignon JP, Arriagada R, Ihde DC, Johnson DH, Perry MC, Souhami RL, Brodin $\mathrm{O}$, Joss RA, Kies MS, Lebeau B, et al. A meta-analysis of thoracic radiotherapy for small-cell lung cancer. N Engl J Med. 1992;327(23):1618-24.

19. Takada M, Fukuoka M, Kawahara M, Sugiura T, Yokoyama A, Yokota S, Nishiwaki Y, Watanabe K, Noda K, Tamura T, et al. Phase III study of concurrent versus sequential thoracic radiotherapy in combination with cisplatin and etoposide for limited-stage small-cell lung cancer: results of the Japan Clinical Oncology Group Study 9104. J Clin Oncol. 2002;20(14): 3054-60.

20. Slotman BJ, van Tinteren H, Praag JO, Knegjens JL, El Sharouni SY, Hatton M, Keijser A, Faivre-Finn C, Senan S. Use of thoracic radiotherapy for extensive stage small-cell lung cancer: a phase 3 randomised controlled trial. Lancet. 2015;385(9962):36-42.

21. Arrieta O, Villarreal-Garza C, Zamora J, Blake-Cerda M, de la Mata MD, Zavala DG, Muniz-Hernandez S, de la Garza J. Long-term survival in patients with non-small cell lung cancer and synchronous brain metastasis treated with whole-brain radiotherapy and thoracic chemoradiation. Radiat Oncol. 2011;6:166

22. Jabbour SK, Daroui P, Moore D, Licitra E, Gabel M, Aisner J. A novel paradigm in the treatment of oligometastatic non-small cell lung cancer. J Thorac Dis. 2011:3(1):4-9.

23. Therasse P, Arbuck SG, Eisenhauer EA, Wanders J, Kaplan RS, Rubinstein L, Verweij J, Van Glabbeke M, van Oosterom AT, Christian MC, et al. New guidelines to evaluate the response to treatment in solid tumors. European Organization for Research and Treatment of Cancer, National Cancer Institute of the United States, National Cancer Institute of Canada. J National Cancer Institute. 2000;92(3):205-16.

24. Schiller JH, Harrington D, Belani CP, Langer C, Sandler A, Krook J, Zhu J, Johnson DH. Comparison of four chemotherapy regimens for advanced non-small-cell lung cancer. N Engl J Med. 2002;346(2):92-8.

25. Ouyang WW, Su SF, Hu YX, Lu B, Ma Z, Li QS, Li HQ, Geng YC. Radiation dose and survival of patients with stage IV non-small cell lung cancer undergoing concurrent chemotherapy and thoracic three-dimensional radiotherapy: reanalysis of the findings of a single-center prospective study. BMC Cancer. 2014;14(1):491.

26. Maemondo M, Inoue A, Kobayashi K, Sugawara S, Oizumi S, Isobe $H_{\text {, }}$ Gemma A, Harada M, Yoshizawa H, Kinoshita I, et al. Gefitinib or chemotherapy for non-small-cell lung cancer with mutated EGFR. N Engl J Med. 2010;362(25):2380-8.

27. Yaqub F. Nivolumab for squamous-cell non-small-cell lung cancer. Lancet Oncol. 2015:16(7), e319.

28. Werner-Wasik M, Swann RS, Bradley J, Graham M, Emami B, Purdy J, Sause $W$. Increasing tumor volume is predictive of poor overall and progressionfree survival: secondary analysis of the Radiation Therapy Oncology Group 93-11 phase I-II radiation dose-escalation study in patients with inoperable non-small-cell lung cancer. Int J Radiat Oncol Biol Phys. 2008;70(2):385-90.
29. Detterbeck FC, Boffa DJ, Tanoue LT. The new lung cancer staging system. Chest. 2009:136(1):260-71.

30. Kong FM, Ten Haken RK, Schipper MJ, Sullivan MA, Chen M, Lopez C, Kalemkerian GP. Hayman JA. High-dose radiation improved local tumor control and overall survival in patients with inoperable/unresectable nonsmall-cell lung cancer: long-term results of a radiation dose escalation study. Int J Radiat Oncol Biol Phys. 2005;63(2):324-33.

\section{Submit your next manuscript to BioMed Central and we will help you at every step:}

- We accept pre-submission inquiries

- Our selector tool helps you to find the most relevant journal

- We provide round the clock customer support

- Convenient online submission

- Thorough peer review

- Inclusion in PubMed and all major indexing services

- Maximum visibility for your research

Submit your manuscript at www.biomedcentral.com/submit
Biomed Central 